\title{
UMA HISTÓRIA DAS CIÊNCIAS FÍSICAS, QUÍMICAS E NATURAIS NO ENSINO SECUNDÁRIO (1882-1950) ${ }^{1}$
}

DOI: http://dx.doi.org/10.1590/2236-3459/75932

\author{
Eva Maria Siqueira Alves' \\ 'Universidade Federal de Sergipe (UFS), Aracaju/SE, Brasil \\ João Paulo Oliveira Gama" \\ "Universidade Federal de Sergipe (UFS), Aracaju/SE, Brasil
}

$\cos 80$

\begin{abstract}
Resumo
Investigar o processo de organização das cadeiras de Ciências Físicas, Químicas e Naturais no período de 1882 a 1950 é o objetivo desse artigo. Para tanto utilizamos como fontes textos normativos da legislação que regulam essas cadeiras no ensino secundário, notadamente em Sergipe, documentos manuscritos como atas, ofícios, relatórios, livro de visitas, dentre outros salvaguardados no Centro de Educação e Memória do Atheneu Sergipense - Cemas, e fotografias de professores em excursões, aulas, laboratórios, gabinetes, reuniões. As palavras e imagens revelam os programas de ensino, os personagens atuantes da história, os momentos que necessitaram registrar práticas das suas aulas no processo de constituição e consolidação das Ciências Físicas, Químicas e Naturais no ensino secundário sergipano.

Palavras-chave: história das disciplinas, arquivos escolares, fotografias, história do ensino secundário, história da educação.
\end{abstract}

\section{UNA HISTORIA DE LAS CIENCIAS FÍSICAS, QUÍMICAS Y NATURALES EN LA EDUCACIÓN SECUNDARIA (1882-1950)}

\begin{abstract}
Resumen
Investigar el proceso de organización de cátedras de Ciencias Físicas, Químicas y Naturales es el propósito de este artículo. Para ello, se utilizan como fuentes textos normativos de la legislación que regulan esas disciplinas en la enseñanza secundaria, en particular en Sergipe, documentos manuscritos como actas, memorandos, informes, entre otros salvaguardados en Centro de Educación y Memoria del Atheneu Sergipense - Cemas, y fotos de profesores en excursiones, clases, laboratorios, oficinas, reuniones. Las palabras y las imágenes revelan los programas de disciplinas, personajes activos en la historia, los momentos en que necesitaron registrarse prácticas de sus clases en el proceso de constitución y consolidación de las
\end{abstract}

\footnotetext{
1 Esse artigo provem da pesquisa "Uma História das Disciplinas Escolares: os conteúdos dos Planos de Estudos na configuração do Ensino Secundário de Sergipe no final do século XIX e início do século XX", financiada pelo CNPq, Edital: 07/2011, Processo CNPq 401306/2011-9.
} 
Ciencias Físicas, Químicas y Naturales en la enseñanza secundaria sergipana.

Palabras clave: historia de las disciplinas, archivos escolares, fotografías, historia de la educación secundaria, historia de la educación.

\title{
A HISTORY OF PHYSICAL, CHEMICAL AND NATURAL SCIENCES IN SECONDARY EDUCATION
}

(1882-1950)

\begin{abstract}
The aim of this article is to investigate the organization process of Physical, Chemical and Natural Sciences subjects during the period of 1882 to 1950 . Therefore, we use as main sources normative texts from the legislation that regulate these disciplines in secondary education, particularly in Sergipe, handwritten documents such as records, letters, reports, guestbooks, among others safeguarded documents at Center of Education and Memory of Atheneu Sergipense - Cemas, and photographs of teachers on field trips, classes, laboratories, offices and meetings. The words and images reveal the syllabus, the characters involved in the story, the moments that they needed to register the practices of their classes in the process of constitution and consolidation of Physical, Chemical and Natural Sciences in secondary education of Sergipe.

Keywords: history of disciplines, school files, photographs, history of secondary education, history of education.

\section{UNE HISTOIRE DES SCIENCES PHYSIQUES, CHIMIQUES ET DE LA NATURE DANS L'ENSEIGNEMENT SECONDAIRE (1882-1950)}

\section{Résumé}

On étudie l'organisation des programmes des Sciences physiques, Chimiques et de la Nature dans la période de 1882 à 1950 où on observe les normes législatives dans l'enseignement secondaire, surtout à Sergipe, des textes manuscrits, des comptes rendus, des bulletins officiels, des circulaires, conservés chez Centro de Educação e Memória do Atheneu Sergipense - Cemas, et des photos de professeurs dans des excursions, en cours, au laboratoire, au bureau, en réunion. Les mots et les images révèlent les programmes d'enseignement, les personnages de l'histoire, les moments nécessaires pour enregistrer les pratiques de leurs classes dans le processus de constitution et de consolidation des sciences physiques, chimiques et naturelles dans l'enseignement secondaire en Sergipe.

Mots-clés: histoire des disciplines, fichiers scolaires, photographies, histoire de l'enseignement secondaire, histoire de l'éducation. 


\section{Introdução}

$\mathrm{O}$

$s$ "papéis velhos", amontoados em um banheiro desativado, anexo à sala da banda escolar, "arquivados" em estantes de ferro, misturavam-se com quinquilharia de objetos, vassoura, papelão, cartazes de isopor... "Espanejando a poeira que testemunha sua antiguidade e seu abandono pelos homens [...] e ouvindo 'cuidado, tem gente aqui!'” (SLENES, 1985, p. 173), iniciamos por organizar a documentação do arquivo histórico do Atheneu Sergipense. ${ }^{2}$

Dentro do processo de construção de um espaço para salvaguardar os documentos da mais antiga instituição de ensino secundário da capital Aracaju/SE, fundada em 1870 e em pleno funcionamento, surgiram uma série de questões que resultaram em variadas pesquisas, entre elas a presente proposta de analisar o processo de organização das cadeiras $^{3}$ de Ciências Físicas, Químicas e Naturais em Sergipe. O artigo dialoga com os escritos de André Chervel (1990, p. 191) ao problematizar o estudo das finalidades de uma disciplina e a busca por analisar os "objetivos fixados" e a "realidade pedagógica". No caso em foco, utilizamos como fontes para compreender os "objetivos fixados" textos normativos da legislação que regulam essas áreas do saber no ensino secundário, documentos manuscritos como atas, ofícios, relatórios, dentre outros arquivados no Centro de Educação e Memória do Atheneu Sergipense - Cemas. ${ }^{4}$ Por outro lado, as fotografias de professores em excursões, aulas, laboratórios, gabinetes e reuniões, bem como os registros no "Livro de visitas" da instituição possibilitam aproximações com uma "realidade pedagógica" vivenciada por uma série de sujeitos que frequentaram de algum modo essa "Casa de Educação Literária" entre o final do oitocentos e a primeira metade do século XX.

Adotamos para auxiliar na compreensão da pesquisa a definição de André Chervel (1990) de disciplina escolar: "A disciplina é aquilo que se ensina e ponto final". (CHERVEL, 1990, p. 178). Ora, se assim consideramos, é possível observar quão amplo é o leque do que se ensina e questões relacionadas também com as concepções de ensino, escola, saberes por ela produzidos e transmitidos. E continua o autor: "Uma 'disciplina' é igualmente, para nós, em qualquer campo que se encontre um modo de disciplinar o espírito, quer dizer de lhe dar os métodos e as regras para abordar os diferentes domínios do pensamento, do conhecimento e da arte". (CHERVEL, 1990, p. 180). Esclarece ainda que o termo no seu uso escolar designou na França até início do século $X X$ a vigilância de condutas.

Nesse sentido, entendemos que mesmo as cadeiras do ensino secundário brasileiro no século XIX e primeiras décadas do XX estavam permeadas por esse "modo de disciplinar o espírito" dos jovens da elite brasileira que estudavam em distintos espaços do Brasil. Sendo que, para averiguar a concretização dessas finalidades, André Chervel

\footnotetext{
2 Santana (2012), investigando as mudanças e permanências na organização e conservação do arquivo escolar do Atheneu Sergipense desde o ano de 1848 a 1926, estabelece uma relação com as práticas administrativas daquela instituição. Aponta a autora para os cuidados, atenção e queixas dos dirigentes expressos nos "relatórios" para com a "conservação dos papéis produzidos".

${ }^{3}$ Denominação que consta em todos os documentos analisados no desenvolvimento da presente pesquisa.

${ }^{4}$ Cabe destacar a assinatura, em 2 de maio de 2013, renovado em 20 de fevereiro de 2017, do "Termo de Convênio de Cooperação Técnica entre a Universidade Federal de Sergipe e a Secretaria de Estado de Educação", com o objetivo de executar atividades de pesquisa, ensino e extensão envolvendo professores e alunos das instituições. Com esse termo, o Cemas é oficialmente institucionalizado, fazendo parte da Proposta Pedagógica do Atheneu Sergipense aprovada pelo Conselho Estadual de Educação. Mais detalhes consultar Alves (2015).
} 
(1990) recomenda um criterioso programa de investigação, alertando para que os estudos não sejam baseados unicamente nos textos oficiais, mas na literatura abundante produzida pelas instituições que põe em ação o desenvolvimento da disciplina. Em outros termos, afirma como objeto da história das disciplinas escolares, a gênese, a função e o funcionamento, e como constituintes de uma disciplina, os conteúdos (o núcleo da disciplina), os métodos de ensino e o aparelho docimológico, sempre atentos às suas finalidades.

Dentro dessa perspectiva a análise das cadeiras de Ciências Químicas, Físicas e Naturais em Sergipe realizada em diálogo com o programa investigativo estabelecido por André Chervel para o estudo da história das disciplinas escolares, contribui para as investigações acerca da história do ensino secundário brasileiro, "visto por dentro", a partir de um lócus investigativo específico, nesse caso, o Atheneu Sergipense. Assim, tem-se uma análise da "gênese, função e funcionamentos" desses saberes que passaram a ocupar um lugar na escola no final do século XIX, como também os seus primeiros desdobramentos. Elementos registrados em diferentes suportes, inclusive nas fotografias.

$\mathrm{Na}$ análise empreendida, consideramos também o que sugere Viñao (2008) para que os pesquisadores avaliem as disciplinas escolares como organismos vivos, e continua:

\begin{abstract}
As disciplinas não são, com efeito, entidades abstratas com uma essência universal e estática. Nascem e se desenvolvem, evoluem, se transformam, desaparecem, engolem umas às outras, se atraem e se repelem, se desgarram e se unem, competem entre si, se relacionam e intercambiam informações (ou as tomam emprestadas de outras) etc. Possuem uma denominação, ou nome que as identifica frente às demais, ainda que em algumas ocasiões, como se tem advertido, denominações diferentes mostram conteúdos bastante similares e, vice-versa, denominações semelhantes oferecem conteúdos nem sempre idênticos. Tais denominações constituem, além disso, sua carta de apresentação social e acadêmica. (VIÑAO, 2008, p. 204, grifos nossos)..$^{5}$
\end{abstract}

Prosseguindo a investigação do "nascer e desenvolver" das cadeiras de Ciências Físicas, Químicas e Naturais, recorremos às fotografias, atentos à crítica externa da produção da imagem bem como a leitura da própria figura, indagando, como sugere Souza (2001): quando e por que tais fotos foram feitas? O que revelam as fotografias do ambiente de práticas escolares? Acrescentamos: por que as fotografias localizadas não estavam preservadas no próprio ambiente que as produziu, o Atheneu Sergipense? ${ }^{6}$

As fotografias escolares constituem um gênero de fotografias muito difundido, a partir do início do século XX, combinado com outros gêneros como os retratos de família, as fotografias de paisagens urbanas, de arquiteturas e os cartões postais. Entre os diversos tipos de conteúdo temático retratados, o mais popular é a foto de classe. Produzidas com finalidade comercial, essas fotografias compreendem um objeto-mercadoria para a recordação. (SOUZA, 2001, p. 79).

\footnotetext{
${ }^{5}$ Outros autores, estrangeiros e brasileiros investigam sobre a temática da História das Disciplinas escolares ou acadêmicas: Alves (2011, 2012), Cassab (2010), Goodson (2003, 2001, 1998, 1990), Julia (2002), Oliveira e Ranzi (2003), Pessanha (2011, 2010, 2004). E ainda: Revista "Tempos e Espaços em Educação" (2010) (http://200.17.141.110/pos/educacao/); o número 34 da Revista "Diálogo Educacional' da PUC-PR (2011). Mais recente temos capítulos na obra de Braghini, Munakata, Oliveira (2017) que investigam objetos científicos utilizados no ensino das ciências.

${ }^{6}$ As fotografias analisadas são cópias dos originais preservados no Instituto Histórico e Geográfico de Sergipe.
} 
No entanto, a falta de informações na reprodução das imagens desafia a interpretação do pesquisador. Ainda que pareçam ser momentos significativos para os professores e alunos retratados nas fotos, estas não apresentam dados identificadores como nomes dos alunos e professores, local e ano da foto, objetivo de deixar registrado aquele momento. "O desaparecimento dos referentes emudecem a imagem que sobrevive apenas com seu conteúdo manifesto". (SOUZA, 2001, p. 80).

Para considerar o "conteúdo manifesto" das fotos, utilizamos como fontes os documentos manuscritos como atas, ofícios, relatórios, dentre outros salvaguardados no Cemas e os textos normativos da legislação que regulam essas cadeiras no ensino secundário.

Tais fontes revelam o movimento de constituição dos vários ramos de conhecimento dentro do Atheneu Sergipense, desvelando sobremaneira personagens dessa história, sujeitos atuantes na configuração de novos espaços dentro da instituição secundária e momentos que necessitaram registrar práticas das suas aulas. As vozes silenciadas naqueles documentos e imagens começaram a falar....

\section{As Ciências Físicas, Químicas e Naturais “nascem e se desenvolvem” no Atheneu Sergipense}

Aguçados pelo acervo de fotografias catalogadas no Cemas, iniciamos a investigação acerca da disposição das cadeiras Ciências Físicas, Químicas e Naturais dentro do conjunto de saberes do Atheneu Sergipense, nos anos de 1882 a $1950 .{ }^{7}$ Contudo, a própria análise das fotografias, aos poucos, nos remetia a outros questionamentos e a busca de outros documentos para dialogar e melhor analisar o ordenamento das referidas cadeiras.

Para tanto, torna-se necessário retroceder ao ano de 1882 quando é incorporada nos planos de estudos do Atheneu Sergipense a denominada cadeira de "Elementos de Sciencias Physicas e Naturaes, Elementos de Physiologia e Hygiene". Com tal inclusão, ampliam-se os estudos secundários de Sergipe, especificamente no tocante as Ciências, possibilitando a formação do "homem cientificamente preparado" descrito por Júlio Ribeiro.

O homem cientificamente preparado deve conhecer, ao menos elementarmente, as mathematicas, a physico-khimica, a bio-physiologia, a psykhologia-moral. Deve ter boas noções de arithmetica, de algebra, de geometria, de mekhanica, de cosmologia, de astronomia sideral e planetaria, de geodesia, de geographia physica, de geologia, de mineralogia, de paleontologia, de botanica, de zoologia, de anatomia, de histologia, de pathologia, de psyhologia, de moral, de anthropologia, de ethnologia, de linguistica, de historia e geographia-historia, de industria, de arte, de litteratura, de sociologia, de legislação, de politica. E mais, deve ter estudos classicos sólidos. (Júlio Ribeiro, 1908. In: MORSE, 1970, p. 212).

Tão pleno e completo plano de estudos nas escolas secundárias não foi uma tarefa fácil desde o início de sua organização, no século XIX. Movimentos de entrada e saída de cadeiras, a restrita presença das Ciências, a alocação nos anos finais, era fato constante, justificando-se que "[...] no Brasil, como nos países europeus, o ensino de Ciências era considerado necessário apenas para as profissões técnicas da indústria, do comércio e da agricultura, enquanto os estudos clássicos eram tidos como apropriados para os estudos

\footnotetext{
${ }^{7}$ A respeito do uso de imagens ver, entre outros, Vidal (2005).
} 
superiores de Medicina e Direito". (LORENZ, 2003, p. 53). Ao ser exigido nos Exames de Preparatórios o saber científico tem maior valorização, tornando-se necessário e constante nos planos das escolas secundárias brasileiras.

Referindo-se a história das ciências, afirma Furtado (2009) sobre as transformações do programa de Ciências Naturais dividido inicialmente em três: História Natural, a Física Experimental e a Química. A aproximação entre a Física e a Química se dava pelas "[...] exposições de objetos e as repetições físicas e químicas frequentemente denominadas experiências realizadas nos diversos estabelecimentos criados para esses fins" (FURTADO, 2009, p. 160), levando a associação em uma só cadeira de Física e Química.

Especificamente sobre a história da Química como ciência e como disciplina escolar no Brasil, os estudos de Scheffer (1997) revelam que com a chegada da Família Real no Brasil, no ano de 1808, há “[...] um enfoque utilitário, e será com essa conotação que ocorrerá a abordagem inicial da química, apenas como ciência acessória à outras áreas como a engenharia, a mineralogia, a metalurgia, as ciências médicas e farmacêuticas". (SCHEFFER, 1997, p. 63). ${ }^{8}$ E prossegue:

[...] assim como das outras ciências exatas e naturais, foi extremamente incipiente, apesar das várias tentativas em implantá-lo, e em dar-lhe importância nos planos de estudos dos diversos estabelecimentos de instrução pública e privada do Império. A natureza do ensino secundário oferecido aos brasileiros com objetivo de preparatório, fez decrescer o valor do ensino da química, marcado pelo número reduzido de alunos que frequentavam a cadeira da qual fazia parte, dividida com 0 ensino de Física. (SCHEFFER, 1997, p. 140).

Em Sergipe, no plano de estudos do Atheneu Sergipense, criado no ano de 1870 com os cursos de Humanidades e o Normal, não havia em princípio os saberes dedicados às Ciências Físicas, Químicas e Naturais. É em sessão extraordinária de 19 de abril de 1882 que toma posse como professor vitalício o médico Daniel Campos para ministrar lições de "Elementos de Sciencias Physicas e Naturaes, Elementos de Physiologia e Hygiene".

Pela série dos planos de estudos construída a partir das fontes identificadas, é possível afirmar que as Ciências Físicas e Naturais esteve presente no Atheneu Sergipense, com uma carga horária de uma hora de aula, durante os anos de 1882 a 1883, voltando a compor o plano em 1890, pelo Decreto de 14 de março.

Com seis anos de duração, o curso de Humanidades do Atheneu Sergipense em 1892 tinha no seu conjunto de conhecimentos as Ciências Físicas, Químicas e Naturais, ministrada no último ano do curso, abordando "Physica e Chimica, noções de Mineralogia e Geologia, Zoologia, Hygiene e Biologia e principaes noções”. (ATA DA CONGREGAÇÃO, 1893. Ref. 481FASS01). Nessa mesma reunião foram organizados os horários, determinando que as aulas da cadeira fossem ministradas das 10 às 11 horas da manhã, nas segundas, quartas e sextas-feiras. Importante verificar que Ciências Físicas, Químicas e Naturais, com os mesmos conteúdos, compõem o quadro dos estudos do terceiro ano do curso Normal, aumentando também o rol de conhecimentos daquele curso. No ano seguinte, a cadeira passa a ser lida diariamente no curso de Humanidades, ampliando a

${ }^{8}$ Mais sobre o ensino da Química como disciplina escolar consultar, entre outros, Aires (2006). 
sua carga horária, ao tempo em que não há registro de que a cadeira das Ciências Físicas, Químicas e Naturais tenha composto o plano do curso Normal.

O ano de 1897 se inicia com novidades. No dia três de fevereiro, a Congregação do Atheneu Sergipense apresentou uma lista de pontos para o concurso aberto para a cadeira das Ciências Físicas, Químicas e Naturais. É o que se segue.

Physica

1. Definição e divisão da Physica, o lugar que ella ocupa na classificação das sciencias. Força attractiva e repulsiva. Diversos estados dos corpos, caracteres de cada estado. Propriedades geraes dos corpos.

2. Movimento e força

3. Attração universal. Lei de Newton. Gravidade, sua direcção, causas que a modificam. Lei da queda dos corpos.

4. Equilibrio dos fluidos. Pressão e impulso dos fluidos. Principio de Pascal. Equilibrio dos corpos fluctuantes. Principio de Archimedes.

5. Calor, medidas da temperatura. Dilatação dos corpos pelo calor. Thermometros. Pendulo compensador.

6. Pressão atmospherica. Barometro.

7. Da luz na propagação e sua intensidade.

8. Da eletricidade, corpos conductores e isoludocso.

Chimica

1. Definição e divisão da Chimica. Corpos simples e compostos. Combinação e mistura. Leis da combinação.

2. Theoria atomica. Affinidade e causas que a modificam.

3. Acidos, bases e saes.

4. Hydrogeneo, Oxygeneo e Ozono.

5. Agua

6. Ar atmosferico

7. Carbono

8. Classificação dos metaes, classificação de Phenosol, classificação natural.

Botanica

1. Definição da Botanica, sua divisão. Tecido celular, fibroso e vascular

2. Estudo geral da haste.

3. Estudo geral da raiz.

4. Estudo geral da folha.

5. Estudo geral da flor.

6. Estudo geral da nutrição vegetal, absorvição, respiração e assimilação.

Zoologia

1. Definição de zoologia. Divisão dos reinos da natureza, seus caracteres distintos

2. Animaes vertebrados, seus caracteres. ${ }^{9}$ (ATA DA CONGREGAÇÃO DO ATHENEU SERGIPENSE, 1897. Ref. 481FASS01). ${ }^{10}$

Com esse extenso rol de temas destacam-se os conhecimentos exigidos para um professor ingressar no Atheneu Sergipense, sinalizando, para a análise em questão, quais os saberes necessários para o ensino das Ciências naquela instituição. Seguindo os ritos prescritos na legislação para a realização dos concursos para professores, a banca examinadora composta por: Geminiano Paes de Azevedo - professor de Francês; Brício Cardoso - professor de Retórica, Poética e Português, e Francisco Teixeira de Faria professor de Matemática, Geometria e Trigonometria, e diante do único candidato inscrito, sorteou o ponto de número 6 da parte da Química - Ar Atmosférico.

\footnotetext{
9 Utilizaremos a grafia do documento original.

10 Os conteúdos de Química, Física e História Natural passam a ser exigidos nos Exames de Preparatórios de Medicina no ano de 1887. (LORENZ, 2003).
} 
Aos vinte dias daquele mês, o farmacêutico Guilhermino Amâncio Bezerra defendeu sua tese sobre o "Ar Atmosférico", seguindo das provas escritas e orais. Avaliado sobre o seu desempenho, por escrutínio secreto, o candidato foi aprovado com distinção, tomando posse perante a Congregação a $1^{0}$ de março daquele ano. Este era, pois, o segundo professor das Ciências Físicas, Químicas e Naturais do Atheneu Sergipense, com a ressalva de ter prestado concurso para a cadeira. Na escrita de sua tese,

[...] o autor deixava claro a importância do ar atmosférico para a existência humana, como "um dos quatro elementos que se reputavam constituitivos da natureza creada, quando nos fins do século XVI foi presentida a complexidade desse elemento, reservando aos "seculos subsequentes as determinações qualitativa e quantitativa do ambiente que respiramos". (BEZERRA, 1897, p. 6, grifos do autor). Ainda, continuava a dissertar sobre as reações químicas e seus produtos ao entrar em contato com o fósforo, carbonato de cálcio, solução frigorífica, além das experiências elaboradas por Lavoisier, Mayow, Scheele, Dumas e Boussingault. O autor afirmava que as pesquisas admitiam existir no ar a presença do oxigênio, azoto, ácido carbônico, e vapor d'água. (SOUZA, 2016, p. 127).

Os concursos transformavam-se em púlpitos para a demonstração intelectual dos candidatos. Ser docente no Atheneu Sergipense significava ser membro do circuito produtor de modelos culturais, ser um dos agentes transmissores, conferindo, em duplo sentido, um status de prestígio intelectual e político.

Mas as transformações relativas aos saberes das Ciências não cessam. Conforme o Decreto 231, de 9 de julho de 1897, sete passam a ser os anos do curso Integral ministrado no Atheneu Sergipense, com as cadeiras de "Sciencias Naturaes, compreendendo Biologia" e "Chimica e Physica", sinalizando uma separação inicial de programas e cadeiras. Destaque-se que é a partir dessa legislação que é expressa a denominação "Física e Química", embora juntas, mas já estabelecendo nomenclatura própria. ${ }^{11}$

Em 1897 no Atheneu Sergipense, os alunos do $6^{0}$ ano do curso deviam fazer exames finais das noções fundamentais de Física e Química, com prova escrita e oral, prestada pelo aluno no final dos estudos de cada cadeira concluída. ${ }^{12}$ Tais exames eram amplamente divulgados na imprensa, no caso dos realizados no Atheneu Sergipense, arrolando os nomes dos membros da banca examinadora, bem como os nomes dos alunos inscritos. Após a realização, nova lista era publicada, constando a nota dos avaliados. Dessa forma, a comunidade externa a instituição passava a ter conhecimento do ritual avaliativo, da prática do julgamento daqueles alunos.

Para as cadeiras de Ciências Físicas e Naturais, História Nacional e Geografia, os discentes prestavam também uma prova prática, de duração de quinze minutos (cf. Art.122, Decreto 231, 1897). A prova escrita, com duas horas de duração, versaria sobre questões compreendidas no programa dos estudos. A prova oral, de meia hora, seria realizada por arguição dos examinadores "sobre ponto sorteado e generalidades da materia" (Art. 122, § $2^{0}$, Decreto 231, 1897). Quanto ao exame de Madureza, este era prestado no final do curso

\footnotetext{
11 No Colégio de Pedro II, no Rio de Janeiro, no ano de 1898, a Física e a Química eram ministradas nos $5^{\circ}$ e $6^{\circ}$ anos do Curso Realista. (VECHIA E LORENZ, 1998).

12 Diferentes são as nomenclaturas e funções relativas aos exames prestados pelos alunos no ensino secundário do século XIX: habilitação, final, classe, suficiência, madureza, admissão, promoção sucessiva. (ALVES, 2006).
} 
pelos alunos aprovados em todos os exames finais. Segundo o mesmo Decreto, as provas versariam sobre Ciências Físicas e sua aplicação: meteorologia, mineralogia e geologia.

Apregoa o Decreto 351, de 9 de junho de 1899 que as aulas de Química e Física, com seis horas de duração fariam parte do rol das cadeiras do $5^{0}$ ano do curso Integral do Atheneu Sergipense, e com duas horas semanais seria ministrada também no $6^{0}$ ano. No entanto, no ano de 1901, a cadeira é ministrada apenas no $5^{\circ}$ ano, reduzindo desta forma a carga horária destinada aos seus ensinamentos. E mais, a alocação das Ciências Físicas, Químicas e Naturais nos últimos anos do curso, que não exigia uma sequência nos estudos, provoca um reduzido número de matrículas nessas cadeiras. ${ }^{13}$

Rege a legislação que os professores deveriam ministrar suas aulas apoiando-se em "Compêndios". Este era o termo mais utilizado para os livros produzidos com finalidade de ensino, sem qualquer pretensão de originalidade. Intitulavam-se também de "Elementos", "Lições", "Manual", "Pontos", "Postilas", "Sinopse", "Tratado", "Preleções". (SOUZA, 1999, p. 39).

A primeira legislação do Atheneu Sergipense (1871) fixa os compêndios a serem utilizados nas aulas das diversas cadeiras. Nas demais legislações não há essa prescrição. Quanto aos compêndios adotados na cadeira examinada, localizamos sinais na Ata da Congregação em 8 de fevereiro de 1902, quando registra que a obra de João Martins Teixeira ${ }^{14}$ deveria ser utilizada para os estudos da Química e Edmond Jean Langlebert para os estudos da Física e História Natural. Evidencia-se que as obras indicadas na escrita das atas da congregação recebiam denominações simplificadas, ou seja, não aparecem expostas outras referências essenciais, como o nome completo do autor, o ano da edição, a editora que o publicou, o que permite inferir que aquelas compunham obras conhecidas da comunidade escolar que as adotaria. ${ }^{15}$

Utilizando outro tipo de fonte, as crônicas de Edilberto Campos (1970), observamos que o autor traz passagens de alguns dos professores do Atheneu Sergipense, quando lá estudou. Referindo-se ao médico José Moreira de Magalhães, professor de Física e Química no Atheneu Sergipense, quando em 1899 cursava o último ano de preparatório, relembra:

Em 1908 reencontrei-o em Aracaju, sempre de fraque, chapéu mole e guarda chuva. Além de cabeçudo, testa larga e cabelo bem aparado. Exercendo a clínica na cidade atendia afável a todos, ricos e pobres. [...] suas aulas eram boas, resumindo a Física de Langlebert e a Química de Martins Teixeira, para poucos alunos do Ateneu [...] (CAMPOS, 1970, p. 60).

Quanto às obras adotadas no Colégio Pedro II no Rio de Janeiro, afirma Lorenz (2003) que:

\footnotetext{
${ }^{13}$ Não podemos atribuir a baixa frequência nas aulas das Ciências "apenas" pela falta de interesse dos alunos em cursarem tais cadeiras, uma vez que não eram exigidas nos Exames de Preparatórios. Deve ser considerado também que tais aulas estavam alocadas nos anos finais do Curso Secundário e não havia a exigência de frequentar todo o curso, somente se o aluno almejasse ter o Diploma de Bacharel.

${ }^{14}$ Schnetzler (1981) afirma que data do ano de 1875, a primeira publicação brasileira de um livro para o ensino de Química nas escolas secundárias. A obra de João Martins Teixeira, "Noções de Química Geral" atingiu 16 edições, até o ano de 1931.

15 Para saber mais sobre a história das ciências consultar Furtado (2009); sobre o ensino da disciplina Química, consultar Aires (2006); quanto a cadeira de Biologia ver Torres (2011); a disciplina Física examinar Sampaio (2004).
} 
[...] para a história natural a lista incluía os textos de Felix Hement, Gabriel Delafosse, e de Edmond Jean Langlebert; este último, fazia parte do Noveau manuel des aspirants au baccalauréat ès sciences. Deve-se também mencionar o livro sobre higiene de Alexandre Lacassagne. Com respeito às ciências físicas, foram citados os manuais de química de Langlebert e de Adolphe Wurtz, e os de física de Claude Servais Pouillet e de Adophe Ganot. Também constava o livro de química de João Martins Teixeira e o de cosmografia de José de Abreu. (LORENZ, 2003, p. 7).

Verifica-se pelas memórias de Campos (1970), que aqueles livros indicados nas atas da Congregação do Atheneu Sergipense, foram utilizados pelos professores em suas aulas. E as obras utilizadas nos estudos secundários do Colégio de Pedro II, eram também adotadas em terras sergipanas.

O Decreto 543 de 9 de outubro de 1906, traz à cena, no texto legislativo, características distintas dos demais, com comentários pedagógicos e indicativos do método a ser seguido pelos professores. Chama a atenção o cuidado, ou talvez a necessidade que tiveram os legisladores de reunir, na mesma peça legal, os conteúdos de cada cadeira e a forma didática em que os professores deveriam desenvolver suas atividades, enunciando, não apenas "o que" devia ser ensinado, os limites de conteúdos, mas também "o como". No capítulo "Dos programmas de ensino", o legislador determina dever o corpo docente do Atheneu Sergipense observar fielmente preceitos metodológicos fundamentais para cada cadeira. Vejamos:

No ramo physico da cadeira de physica e chimica se ensinarão os factos do domínio da gravidade, do calor, da acustica, da optica, da electricidade e do magnetismo.

O ensino da chimica começara pelo da mineral e passará ao da organica.

Fará objecto da primeira parte depois do estudo da nomenclatura e notação chimica, do das leis da combinação e do da doutrina atomica, o dos principaes metalloides e metaes e dos respectivos compostos. A segunda parte tratará da composição, constituição e classificação dos corpos organicos, das formulas organicas, dos radicais, das series organicas e das funcções chimicas em geral. (Art. 6, VII, Decreto $543,1906)$.

Tais prescrições permanecem em Decretos dos anos seguintes. Para a História Natural:

[...] comprehendera na mineralogia o estudo da chrystalisação e suas leis, e dos systemas chrystalinos, o exame dos mineraes, seus caracteres morfológicos, a disgnação das espécies mineraes e sua classificação.

$\mathrm{Na}$ geologia se discriminarão as rochas, segundo sua origem, composição mineralogica e estrctura, e se explicará a formação dos estractos rudimentares e a chronologia geologica.

$\mathrm{Na}$ Botanica, além da parte geral desta sciencia, se fará o estudo das mais importantes famílias vegetaes, servindo como exemplares para isso plantas frescas das espécies mais comuns.

$\mathrm{Na}$ Zoologia, das nocções relativas aos tecidos, orgams, apparelhos, systemas e funcções dos animais se passará ao estudo das espécies e sua taxionomia e á succinta descripção dos typos da serie animal. (Art. VIII, Decreto 556, 1908).

Mesmo definindo e delimitando os conteúdos a serem trabalhados pelo professor em sala de aula, a legislação abre espaço para que "os lentes do Atheneu Sergipense [adotem] acessoriamente quaesquer modos pedagogicos, cuja alta conveniencia na transmissão do ensino a experiencia haja demonstrado". (Art. $7^{\circ}$, Decreto 543,1906 ). Possibilita, assim, que a experiência e os conhecimentos dos professores pudessem ser 
empregados em benefício dos estudos.

No contínuo movimento de organização da cadeira, pelo Decreto 563 de 12 de agosto de 1911, passa a denominar-se "Physica e Chimica e Noções de Hygiene", lecionada nos $5^{\circ}$ e $6^{\circ}$ anos com quatro horas semanais, fixando a legislação que o programa do ensino deveria atender, além daquelas determinações exposta no Decreto de 1906, as seguintes linhas:

O programma de Physica e Chimica e Hygiene se restringirá ás noções succintas sobre os phenomenos de que tratam. O ensino dellas será quase intuitivo, despido de doutrinas e theorias, sendo destinada a mor parte dos programmas ás demonstrações e experiências. [...] $\mathrm{O}$ estudo de Hygiene deverá conferir ao estudante as principaes noções da hygiene individual, de hygiene collectiva, de hygiene profissional, das molestia contagiosas, das enfermidades adquiridas no contacto com os animaes. Não se esquecerão também as grandes linhas de prophylaxia. (Art. $2^{\circ}$, e, Decreto 563,1911 ).

No ano seguinte, novo Decreto foi fixado, provocando a reorganização dos programas por parte dos professores do Atheneu Sergipense. Assina o programa para a cadeira de Física, Química e Higiene, o médico Aristides da Silveira Fontes. Seguem os conteúdos de Química e Higiene: ${ }^{16}$

\begin{abstract}
Chimica
Composição dos corpos. Corpos simples e compostos. Mineraes e organicos. Misturas e ligas. Hydrogeneo. Constituição dos corpos: atomos e affinidade; moleculas e cohesão. Estudo dos corpos. Fluor e seus principaes compostos. Composição e decomposição: phenomenos que os acompanham e circunstancias influenciam. Analyse e syntese. Noções geraes sobre a synthese organica. Bromo e seus principaes compostos. Lei da chimica: proporções definidas; das proporções multiplas; dos meios proprios; leis thermicas e seos volumes. Oxygeneo e ozona. Nomenclatura chimica. Estudo da agua. Notação chimica: simbolos, formulas e equações. Isonomia. Enxofre e seos compostos. Radicaes, typos e series. Ar athmosferico. Propriedades physicas e organolopticas dos corpos. Phosphoro e seos compostos. Propriedades chimicas e reações. Assenico, antimonio e seos compostos. Estudo geral dos acidos, bases e saes. Carbono e seos compostos. Classificação dos elementos: metaes e metalloides. Potassio, sodio e seos compostos. Classificação dos corpos organicos: funcções. Ferro e cobre. Minereo e chumbo. Generalidades sobre os hydrocarbonetos. Generalidades sobre os alcoes. Generalidades sobre os aldehydos. Generalidades sobre os acidos organicos. Generalidades sobre os etheres.

Hygiene

O meio natural. Athmosfera. Sólo.

Hygiene da habitação.

Hygiene da alimentação. Regras geraes da alimentação. [?] principaes de certos alimentos usuaes. Perigos de certos materiaes alimentares como peixes, crustáceos, moluscos e leite. Regimes especiais. Perigo do tabaco.

Agua.

Hygiene do corpo. Vestimentas. Cuidados. Exercícios physicos.

Molestias contagiosas. Prophylaxia. (ATA DA CONGREGAÇÃO DO ATHENEU SERGIPENSE, 28 de fevereiro de 1913, Ref. 481FASS01). ${ }^{17}$
\end{abstract}

\footnotetext{
${ }^{16}$ Naquele momento não havia a profissionalização dos professores do ensino secundário; assim profissionais como médicos, engenheiros, farmacêuticos, advogados, assumiam as cadeiras do ensino secundário, tanto em outras instituições brasileiras como também no Atheneu Sergipense.

17 Consta nessa mesma ata e em atas seguintes os programas de Português, Francês, Aritmética, Álgebra, Geometria e Trigonometria, Geografia, Lógica e Direito Público, Moral e Instrução Cívica, História Natural, História Universal e do Brasil, Latim.
} 
Nesse registro há uma descrição minuciosa dos conteúdos a serem trabalhados, evidenciando a necessidade de explicitar, além dos preceitos da legislação, mais detalhes na organização dos programas das cadeiras que deveriam avançar dos conhecimentos teóricos para também uma abordagem mais prática.

As modificações também ocorreram na escrita dos textos legislativos. Em 1916 há o cuidado de explicitar que as lições das Ciências Físicas, Químicas e Naturais deviam ser ministradas com "experiencias interessantes e com exemplares typicos" (Art. 209, Decreto 630, 24 de abril de 1916), apontando uma necessidade de lugares específicos para 0 desenvolvimento das aulas, os futuros laboratórios.

Por esse Decreto, quatro eram os cursos oferecidos no Atheneu Sergipense: Ginasial - feito em cinco anos, para os candidatos aos cursos das Escolas de Ensino Superior da República; Integral - de seis anos, para os que, não podendo ou não querendo seguir as profissões proporcionadas por aqueles cursos, se destinassem a outras de sua escolha; Normal - de quatro anos, para os candidatos ao professorado do ensino primário do sexo masculino; Comercial - de três anos para os que se destinassem aos diferentes ramos do comércio. Nos $4^{\circ}$ e $5^{\circ}$ anos do curso Ginasial e Integral, a cadeira de Física e Química era lecionada. No último ano do curso Integral, deveria haver a "recapitulação da matéria dada e suas applicações ás industrias uzuaes." Sugeria mais uma vez o Regulamento, a aplicação prática dos conteúdos lecionados.

De acordo com as determinações da Reforma Rocha Vaz, novo Regulamento é baixado em 12 de dezembro de 1925, determinando como fim do Atheneu Sergipense "ministrar a instrução de humanidades indispensável ao exame vestibular nos estabelecimentos de ensino superior, e também conferir o diploma de bacharel em ciências e letras" (Art. $\left.1^{\circ}\right)$. No conjunto das cadeiras, o Regulamento propunha três horas semanais para Física, ministrada nos $4^{\circ}$ e $5^{\circ}$ anos e, separadamente, três horas para Química, também nos $4^{\circ}$ e $5^{\circ}$ anos. Separam-se as cadeiras de Química, Física e História Natural, ganhando ampliação de carga horária e autonomia, com experiências realizadas nos laboratórios e gabinetes, "entrando o ensino teórico como reforço às demonstrações desenvolvidas". (Art. 24, § 6², Decreto 912, 1925).

Por determinação legal dos anos de 1921, 1925 e 1926, o Atheneu Sergipense contaria com uma biblioteca, a cargo do escriturário-bibliotecário e especialmente destinada ao uso do corpo docente e discente, formada de livros, mapas, memórias, impressos ou manuscritos relativos às cadeiras professadas e também de exemplares das obras didáticas adotadas. A escola possuía museu, biblioteca, gabinetes de Física, Química, História Natural, de modo que os programas de ensino fossem desenvolvidos com aplicações práticas.

Em diferentes relatórios encaminhados anualmente à Direção da Instrução Pública, a Direção do Atheneu Sergipense descreve as condições físicas dos gabinetes e laboratórios, destacando a carência de materiais adequados para aulas práticas das Ciências Físicas, Químicas e Naturais:

Além de ser a casa insuficiente insegura e de aspecto miserável, falta-lhe o material pedagógico necessário a um ensino proveitoso. Não será exagero dizer que não temos gabinetes de física e química e história natural, pois o que no estabelecimento existe com este nome adquirido na administração de Rodrigues Dórea [1911], é antes uma colecção de objectos na sua maioria imprestáveis. (LIVRO DE 
CORRESPONDÊNCIAS DO ATHENEU SERGIPENSE, 1922-1932. Ref. 193FASS05).

A preocupação da direção recebe reforço na Lei 978, de 10 de novembro de 1926 que autorizava o Governo a reorganizar os gabinetes de Física e História Natural, o laboratório de Química e a adquirir os instrumentos precisos para o ensino de Geografia, Cosmografia e Desenho, disponibilizando créditos orçamentários. ${ }^{18}$

De modo a utilizar tais recursos, o professor Antônio Tavares de Bragança elaborou uma lista de "material scientifico para o estudo pratico" necessários para os Gabinetes de Física, Química, História Natural, Geografia e Cosmografia. No início do ano de 1930 o Diretor do Atheneu Sergipense, Leandro Diniz do Faro Dantas, solicitou ao Secretário Geral do Estado um funcionário da Fazenda Estadual para fiscalizar a abertura dos caixões contendo os materiais adquiridos, além de convidar também o Professor Farmacêutico Álvaro da Silveira Britto para assistir a instalação dos trabalhos de catalogação dos materiais para os respectivos gabinetes. Meses depois, a demanda foi por: retificadores de corrente, acumuladores, transformador de corrente, pedras de mármore e tubos de borracha, para instalar os equipamentos nos gabinetes de estudos práticos das ciências. (LIVRO DE CORRESPONDÊNCIAS EXPEDIDAS, 1930. Ref.193FASS05).

Para desenvolver as aulas dessas áreas do conhecimento, contava o Atheneu Sergipense no seu quadro administrativo com um Preparador e Conservador para as cadeiras de Física, Química e História Natural, de livre nomeação do Governo. Desempenhavam tais funções, segundo relatório do ano de 1930 do Diretor Leandro Diniz, Álvaro da Silveira Britto e Lourival Bonfim. Com tais sujeitos, demonstra a direção da instituição a preocupação por aulas com experiências práticas. Porém, a condição essencial para exercer essa função seria a de ter exames das cadeiras respectivas, prestado em qualquer instituto oficial ou equiparado ao Ginásio Nacional. Cabia aos preparadores ter os materiais do gabinete catalogados e limpos, sempre dispostos ao uso dos professores, fazer as demonstrações práticas nas aulas e:

a) ter todos os objetos dos gabinetes catalogados e dispostos na melhor ordem e estado de asseio;

b) preparar as coleções e dispor a aparelhagem necessária à realização das práticas das aulas, conforme instruções do professor;

c) cumprir o que lhe fôr determinado, relativamente ás demonstrações praticas;

d) auxiliar o serviço da aula, dando as aulas práticas que Ihe forem determinadas pelo professor da cadeira. (Art. 114, Decreto N. 7 de 14 de março de 1938). ${ }^{19}$

A preocupação por equipar da melhor forma os gabinetes para as aulas práticas é referida na mensagem do Governador do Estado de Sergipe, Eronildes Ferreira de Carvalho em relatório apresentado à Assembleia Legislativa no ano de 1936. Verifica o governante da necessidade de ampliação dos gabinetes de História Natural, Física e Química, alegando que o número elevado dos alunos em cada turma, tornava impraticável

\footnotetext{
18 Há registro de que o professor Franco Freire, Diretor Geral da Instrução Pública ofereceu uma coleção de minérios e rochas devidamente classificadas para os gabinetes de Física, Química e História Natural.

19 É a partir do Decreto 351 de 9 de junho de 1898 que aparece no quadro do pessoal administrativo do Atheneu Sergipense a figura do Preparador, indicando possivelmente ser o início da organização dos "Gabinetes de Física, Química e História Natural", demonstrando mais uma vez a preocupação por aulas com experiências práticas.
} 
o funcionamento das aulas. No ano seguinte assim expõe:

Foram proporcionadas ao Atheneu "Pedro II", nosso estabelecimento oficial de ensino secundário, as instalações de ordem techinica julgadas necessárias, tudo dentro dos moldes da moderna pedagogia, não se visando o tamanho dos sacrifícios de ordem financeira.

[...] para os gabinetes de Physica e Chimica e de Historia Natural formam adquiridos vários aparelhos, dentre os quaes três microscópios para completarem a instalação techinica do gabinete de Historia Natural.

O corpo docente do Atheneu "Pedro II" está constituído de 31 professores, além de um auxiliar (assistente de Physica e Chimica e de História Natural). (CARVALHO, 1937, p. 41).

Uma das imagens (Figura 01) que revelam aulas práticas, "[...] instantes congelados de uma trajetória institucional" (SOUZA, 2001, p. 80) reflete o Gabinete de Química expondo a bancada, bancos de madeira, aparelhos, louças e frascos de substâncias, materiais necessários às práticas daquela cadeira e que foram adquiridos pela escola a partir de pedidos dos professores da mesma. Ainda na leitura da imagem 1, de jaleco e gravata aparecem dois sujeitos do quadro administrativo, o "preparador" e o "conservador" (não identificados), responsáveis pela manutenção do ambiente. Em outro momento, na imagem 2, o registro revela o Gabinete de Química com uma bancada não mais de madeira e sim de alvenaria, aparentemente com os mesmos bancos, porém em outro espaço, observado pela disposição da porta.
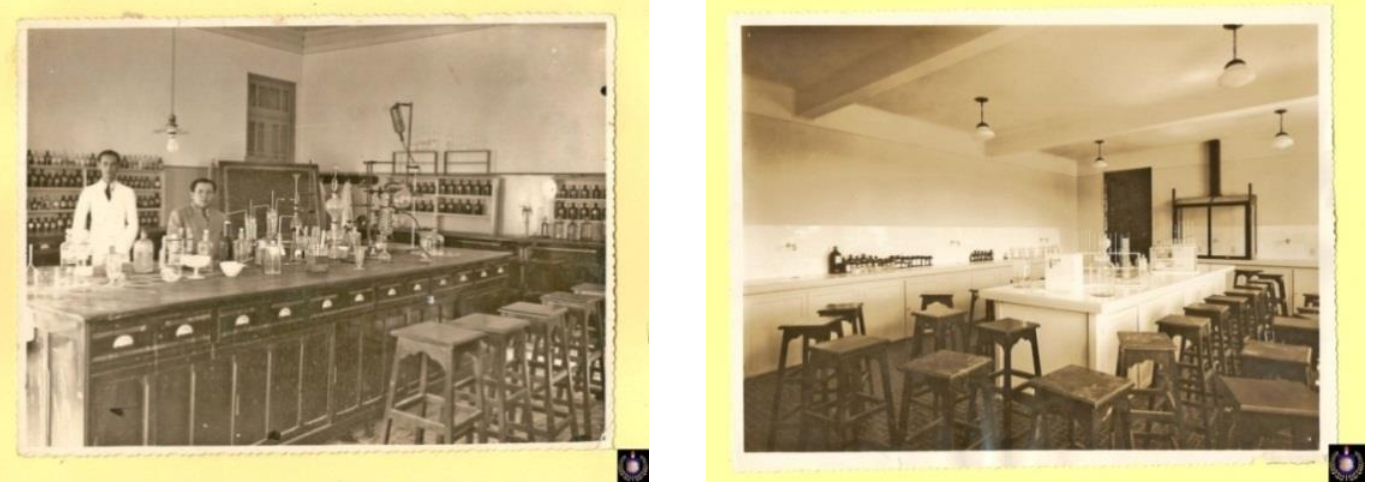

Figura 01 - Imagens 1 e 2 do Gabinete de Química do Atheneu Sergipense (s/d).

Fonte: Acervo do Cemas.

Em setembro de 1938 a Congregação do Atheneu Sergipense aprova a lista de pontos de vários concursos e dentre eles o concurso para preenchimento da cadeira de Ciências Físicas e Naturais, elencando os seguintes temas: 1. Água; 2. Oxidações e reduções; 3 . Teorias sobre a origem da terra - crítica; 4 . Reprodução e disseminação dos vegetais em geral; 5 . Estudo físico-químico e biológicos do calor; 6 . Hidrogênio; 7. Ácidos, bases e sais; 8. Metalurgia do ferro - problema siderúrgico do Brasil; 9. Fósseis especialmente paleontropológico; 10. Das sociedades biológicas; 11 . Os sentidos do homem; 12. O carbono em a natureza; 13. Solo; 14. A divisão do trabalho biológico; 15. Fenômenos magnéticos; 16. Oxigênio; 17. Trigo, açúcar, café, algodão e borracha; 18. Higrometria; 19. Substancias minerais e orgânicas, seres organizados; 20. Alimentos.

Naqueles meses finais do ano de 1938 ocorreram as diferentes provas: de títulos, 
escrita, oral e prática. Dois foram os concorrentes aprovados, o Engenheiro de Minas e Civil José Rollemberg Leite que defendeu a tese "A natureza da luz", com nota final de 9,96 e o Médico João Antônio de Aquino com nota 8,28 e tese "A atmosfera". (ATAS DA CONGREGAÇÃO DO ATHENEU SERGIPENSE, 1938. Ref. 496FASS01).

Concluído o concurso, José Rollembergue Leite assumiu a função de professor catedrático de Ciências Físicas e Naturais do Atheneu Sergipense, em dezembro de 1938, mas também transitou por outras cadeiras como a de Química no ano seguinte e a de Matemática em 1940.

Retomando as imagens, observamos nas seguintes (Figura 02), que o evento exposto é uma aula de Física, tendo na imagem 3, à frente, alunos homens e mulheres, elegantemente fardados, sentados em suas carteiras tendo ao fundo uma bancada de madeira com instrumentos e o professor de terno e gravata. Já a imagem 4 revela o mesmo espaço, porém de outro ângulo, podendo visualizar um grande armário com variados aparelhos e vidrarias.

As imagens expostas não apresentam datas, porém por meio de outros sinais, revelam elementos como atividades práticas e saberes necessários em aulas no Gabinete de Química e aulas de Física, entre as décadas de 1930 a 1950.
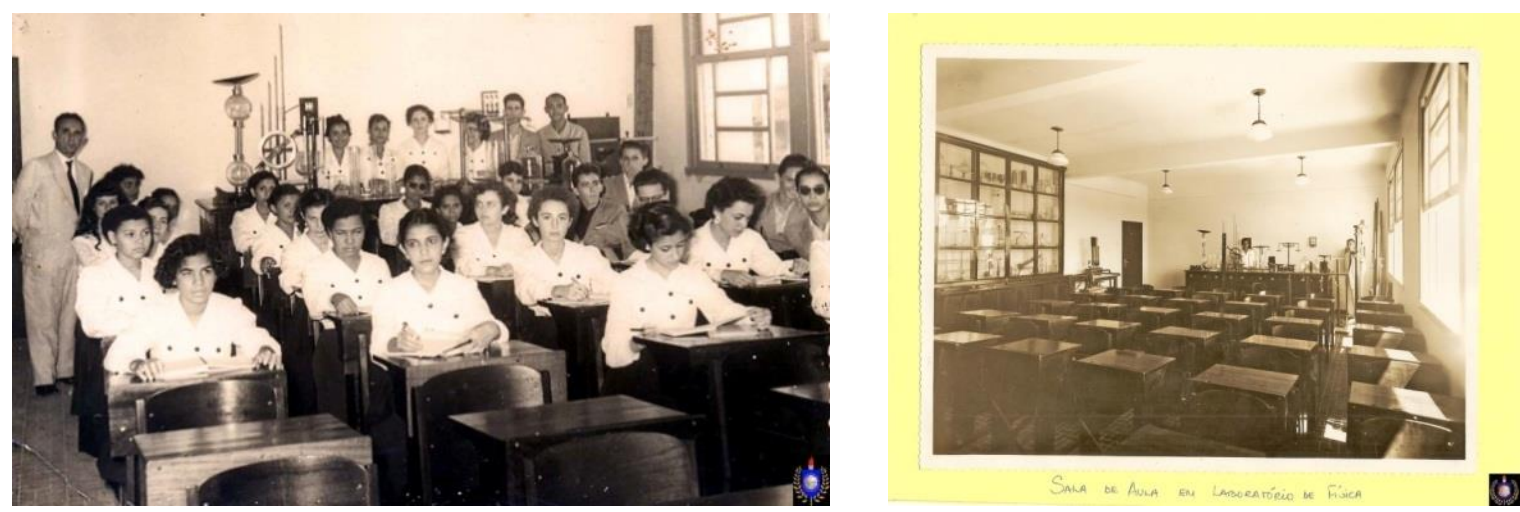

Figura 02 - Imagens 3 e 4 da aula de Física do Cirurgião Dentista João Alfredo Montes. Atheneu Sergipense (provavelmente 1954).

Fonte: Acervo do Cemas.

Investigando instrumentos utilizados no ensino da Física e Química no Colégio Culto à Ciência de Campinas/SP, Meloni (2011) compara os inventários com catálogos de fabricantes, comprovando como um dos fornecedores dos materiais de Física "Les Fils D’Émille Deyrolle", a "Maison Deyrolle" de Paris, ao tempo em que os instrumentos para as aulas de Química tinham maior procedência dos fabricantes alemães. Muito embora havendo semelhanças nos aparelhamentos da instituição campineira com os da escola sergipana, ainda não está identificada a origem dos equipamentos adquiridos para as aulas das Ciências Física, Química e História Natural do Atheneu Sergipense. ${ }^{20}$

A imagem seguinte (Figura 03) revela o Gabinete de História Natural, com destaques aos alunos homens dispostos à frente, porém vendo entre eles, quase que escondidas, duas alunas mulheres. No armário há animais empalhados, um quadro do

20 Inspirados em Meloni (2014), iniciamos o trabalho investigativo de identificar os "objetos das ciências" do Atheneu Sergipense. 
corpo humano, além de expositor que provavelmente guardava outros itens essenciais às aulas daquele saber científico.

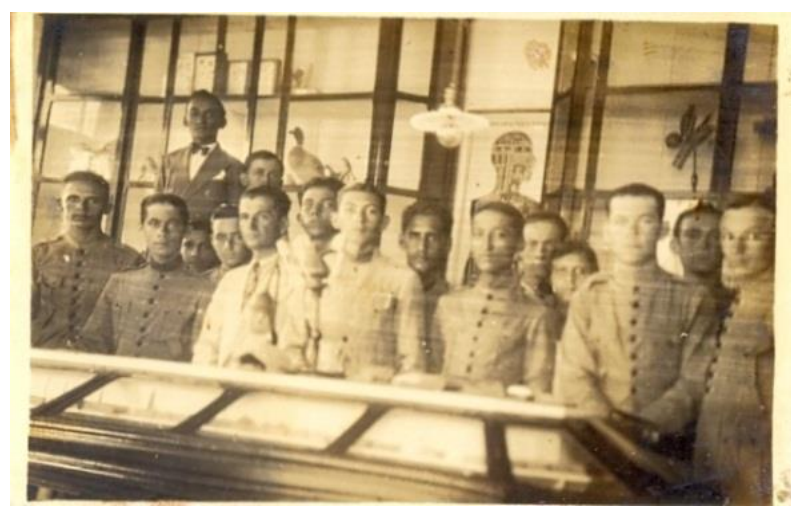

Figura 03 - Gabinete de História Natural. Atheneu Sergipense (s/d).

Fonte: Acervo do Cemas.

Em diferentes outras fontes identificam-se traços das aulas das Ciências Física, Química e Natural no Atheneu Sergipense. Especificamente no Livro de Registro de Títulos (1904-1940) içamos que Augusto Maynard Gomes, Interventor Federal em março de 1935, nomeou o Cirurgião Dentista João Alfredo Montes (Imagem 3, na Figura 02), que ocupava interinamente a cadeira de Física, para professor catedrático, baseado nas informações prestadas pelo diretor da escola quanto a sua idoneidade intelectual, capacidade pedagógica e aplicação ao ensino. Ainda dessa mesma fonte nota-se que o Engenheiro de Minas José Rollemberg Leite foi nomeado professor catedrático efetivo de Ciências Físicas e Naturais no ano de 1938. Antônio Tavares de Bragança e Lucilo Costa Pinto foram professores de Química e Oscar Batista do Nascimento de História Natural no período de 1937 a 1942.

Com base nos estudos de Oliveira (2015), a partir das memórias de Manoel Cabral Machado, assim descreve seus professores do Atheneu Sergipense na década de 1930: "Oscar Nascimento representava um professor do tipo clássico, sempre metódico e objetivo. [...] Zequinha Carvalho tinha fama de reprovador, com a sua aposentadoria, os conhecimentos da Química foram para o domínio de Tavares Bragança, "um cientista com fama de pesquisador". (OLIVEIRA, 2015, p. 108).

Constantemente há registro de professores que mudavam de cadeiras, quer por licença do que anteriormente era o responsável, quer também por determinação ou pedido dos professores e diretores do Atheneu Sergipense. Exemplificando, apontamos o caso do professor Aristides da Silveira Fontes, sendo nomeado em 1905 para reger Geografia Geral e Cosmografia do Brasil, depois passa a lecionar Mecânica e Astronomia (1907), Física, Química e Higiene (1911) e em 1925 Física e Química.

No início dos anos de 1930, nova lei educacional é posta em vigor. Trata-se da Reforma Francisco Campos oficializada pelo Decreto $\mathrm{n}^{0} 18.890$ de 18 de abril de 1931, que:

[...] conferiu, em nível legal, organicidade ao ensino secundário brasileiro por meio de várias estratégias curriculares inovadoras, dentre as quais destacamos o aumento da duração do curso secundário, a seriação rigorosa das "disciplinassaber", a frequência obrigatória dos alunos, a imposição de um detalhamento e 
regular sistema de avaliação discente e a reestruturação do sistema federal de inspeção federal. (DALLABRIDA; SOUZA, 2014, p. 13).

Em vigor no período de 1931 a 1942, tal reforma estabelecia o ensino secundário composto pelos cursos Fundamental com duração de cinco anos e Complementar com dois anos. O Curso Complementar, dividido em Pré-jurídico, Pré-médico e Pré-politécnico, oferecia aulas nas sessões de Direito, Medicina e Engenharia, respectivamente. Nesses cursos, ofertados no Atheneu Sergipense, em atendimento à lei Nacional, há a presença de Física e Química e História Natural nas sessões de Medicina e Engenharia, conferindo peso às Ciências.

$\mathrm{Na}$ década de 1930, contava o Atheneu Sergipense com o seguinte corpo administrativo: um diretor, um vice-diretor, um secretário, um escriturário-arquivista, um escriturário-tesoureiro, um escriturário-bibliotecário, um chefe de disciplina, seis inspetores de alunos, duas inspetoras de alunas, conservador dos gabinetes, datilógrafo, porteiro, dois serventes e dois encarregados. Anota-se em Livro de Registro de Títulos (1904 a 1940) no ano de 1937 a nomeação de vários funcionários para atuarem especificamente com cargos administrativos diretamente no Curso Complementar, tais como: secretário, porteiro, inspetor de alunos e alunas, conservador de gabinetes. São esses os agentes que colocaram o Curso Complementar em funcionamento com atenção aos Gabinetes de Química, Física e História Natural.

A análise das cadeiras das Ciências Físicas, Químicas e Naturais ampara-se ainda em apontamentos feitos por sujeitos que visitavam o Atheneu Sergipense, roteiro indispensável para aqueles que por terras sergipanas passassem, registrando suas impressões no "Livro de Visitas". (ALVES, 2004). ${ }^{21}$

Seduzia sobremaneira tais visitantes as aulas nos gabinetes e laboratórios de Física, Química e História Natural, especialmente porque, para Alberto Andrada, professor da Escola de Minas de Ouro Preto, esses laboratórios quando existiam nos Ginásios eram os mais pobres. Porém alegrou-se ao vê-los aparelhados no Atheneu Sergipense:

Fica assim, o estudo da Physica e da Chimica reconduzido á sua verdadeira orientação: a Physica ensinada semelhante á Physica creada, em que o phenomeno e a experiencia são o pedestal de tudo. Em torno destes e sobre estes é que se constroem as theorias que explicam e, freqüentemente, os trazem á luz, theorias tão subordinadas aos factos concretos, aos phenomenos que um só destes, que por ellas seja inexplicavel e as contradiga, basta para as lançar por terra.

Seguindo a mesma sequencia, a Physica estudada só será sabida da verdade si o phenomeno visto der razão da theoria que o explica. $O$ apparelhamento do laboratorio de Physica e Chimica do Atheneu Pedroll já permite que os conhecimentos dessas disciplinas vão se erguendo na mente do alumno equilibradamente, numa verdadeira construção segura que se forma de factos sobre factos, argamassados pelas teorias que os reunem e os ligam num todo organico que é a Physica. Alberto Andrada. (Livro de Visitas, 30 de junho de 1933).

Enaltece o visitante as boas condições e aparelhamento dos laboratórios de Física e Química do Atheneu Sergipense, ressaltando a "verdadeira orientação" dos

${ }^{21}$ Em relatório do ano de 1890, como Diretor Geral da Instrução Pública do Pará, José Veríssimo menciona que nos Estados Unidos era comum levar os deputados, nas cidades que chegavam, a visitarem os estabelecimentos de instrução, pois queriam "assim os Estados-Unidos não só revelar o seu interesse pelas coisas do espirito, como dar aos ilustres estrangeiros a prova de que a sua civilização não é exclusivamente industrial". (VERISSIMO, 1890, p. 135). 
ensinamentos teóricos e práticos realizados naqueles espaços.

\section{Considerações finais}

Instigados inicialmente pela contemplação das fotografias que revelam momentos das aulas das Ciências Físicas, Químicas e Naturais, investigamos o processo de organização dessas cadeiras no Atheneu Sergipense, dialogando com outras fontes, como os textos normativos da legislação que regulam esses ramos do saber no ensino secundário, e documentos manuscritos como atas, ofícios, relatórios referentes ao Atheneu Sergipense.

As cadeiras analisadas, tal como adverte Viñao (2008), nasceram, se desenvolveram, evoluíram, se transformaram, englobaram umas às outras, se atraíram, se repeliram. De Elementos de Sciencias Physicas e Naturaes, Elementos de Physiologia e Hygiene de 1882, aos laboratórios de Física, Química e História Natural nas décadas de 1940 e 1950.

Todo esse movimento contou com a atuação dos professores, diretores, legisladores, sujeitos que declaravam insuficientes os espaços e materiais necessários para as aulas das Ciências Físicas, Químicas e Naturais ministradas no Atheneu Sergipense.

As legislações e imagens fotográficas são analisadas juntamente com as crônicas e palavras dos visitantes que se impressionavam com os gabinetes de Física, Química e História Natural. Avaliaram como modernos, equipados, que atendiam às necessidades e finalidades experimentais, com "excellencia dos methodos de ensino, a facilidade de suas exposições, mas também o aproveitamento admirável e admirado dos alumnos que são em verdade o reflexo dos mestres, salvo as excepções oriundas de factores outros", expressa Dr. Antonio Dias de Moraes no Livro de Visitas em 10 de setembro de 1927.

Por fim, os "papéis velhos", a documentação salvaguardada no Centro de Educação e Memória do Atheneu Sergipense possibilitou desenhar uma história das Ciências Físicas, Químicas e Naturais no ensino secundário de Sergipe. Traços do seu processo de constituição e consolidação vistos por meio da análise dos constituintes de uma disciplina escolar apontados por André Chervel. Uma história, entre tantas outras que ainda podem ser escritas e reescritas sobre a História das Disciplinas, a História do Ensino Secundário, a História da Educação, com seus diferentes sujeitos, em distintos espaços e temporalidades.

São as vozes, antes silenciadas naqueles documentos e imagens, que permanecem falando... escutem....

\section{Referências}

ALVES, Eva Maria Siqueira (Org.). Entre papéis e lembranças: o Centro de Educação e Memória do Atheneu Sergipense e as contribuições para a história da educação. Aracaju: Edise, 2015.

ALVES, Eva Maria Siqueira, SANTANA, Sayonara Rodrigues do Nascimento (Orgs.).

Cemas, Centro de Educação e Memória do Atheneu Sergipense. Acervo Digital, 2012.

ALVES, Eva Maria Siqueira. A configuração da disciplina escolar Matemática. Revista

Tempos e Espaços em Educação, São Cristóvão, v. 4, p. 121-132, jan./jul. 2010. 
. A produção em história das disciplinas nas pesquisas de Sergipe. In: BERGER, Miguel André; NASCIMENTO, Ester Fraga Vilas-Bôas Carvalho do. Imprensa, impressos e práticas educativas: estudos em história da educação. Fortaleza: UFC, 2012. p. 137-162.

. Aspectos históricos do ensino de Química nos estudos secundários de Sergipe.

Cadernos UFS: Química e Educação, São Cristóvão, v. 6, fasc. 2, p. 97-111, 2004.

Imagens imortalizadas pelas palavras. Educar em Revista, Curitiba/PR, Ed. da UFPR, n. 24, p. 227-244, 2004.

. 0 Atheneu Sergipense: uma casa de educação literária examinada segundo os planos de estudo (1870/1908). 2005. 318 f.Tese (Doutorado em Educação) - Programa de Pós-Graduação em Educação: História, Política e Sociedade, Pontifícia Universidade Católica, São Paulo, 2005.

Sistema de avaliação discente nos estudos secundários (1870-1900). In: CONGRESSO LUSO-BRASILEIRO DE HISTÓRIA DA EDUCAÇÃO (COLUHBE), 6, 2006, Uberlândia. Anais... Uberlândia: Universidade Federal de Uberlândia, 2006. Disponível em: <http://www2.faced.ufu.br/colubhe06/anais/arquivos/363EvaMariaAlves.pdf>.

ALVES, Eva Maria Siqueira; OLIVEIRA, João Paulo Gama; TELES, Igor Pereira. O Centro de Educação e Memória do Atheneu Sergipense: contribuições para a história da educação. Revista da Fapese, Aracaju, v. 4, n. 1, p. 79-88, 2008.

AIRES, Joanez Aparecida. História da disciplina escolar química: o caso de uma instituição de ensino secundário de Santa Catarina (1909-1942). 2006. 265 f. Tese (Doutorado em Educação) - Programa de Pós-Graduação em Educação da Universidade Federal de Santa Catarina, Florianópolis, 2006.

BRAGHINI, Katya; MUNAKATA, Kazumi; OLIVEIRA, Marcos (Orgs.). Diálogos sobre a história da educação dos sentidos e das sensibilidades. Curitiba: Ed. UFPR, 2017.

CARVALHO, Eronildes Ferreira de. Mensagem apresentada à Assembleia Legislativa do Estado de Sergipe. Aracaju, Imprensa Oficial, 1937.

Mensagem apresentada à Assembleia Legislativa do Estado de Sergipe. Aracaju, Imprensa Oficial, 1936.

CEMAS, Centro de Educação e Memória do Atheneu Sergipense. Livro de Atas da Congregação (1871-1916). Ref. 481FASS01 496FASS01.

Livro de Atas da Congregação do Atheneu Sergipense (1916-1939). Ref.

Livro de Atas da Congregação do Atheneu Sergipense (1945-1962). Ref. 120FASS01.

. Livro de Atas de Concursos para professores (1926-1930). Ref. 433FASS01.

Livro de Correspondências expedidas do Atheneu Sergipense (1898-1916). Ref. 74FASS05.

Livro de Correspondências expedidas do Atheneu Sergipense (1916-1922). Ref. 981FASS05.

Livro de Correspondências expedidas do Atheneu Sergipense (1922-1932). Ref. 193FASS05.

Livro de Registro de Títulos (1904-1947). Ref. 402FASS09.

Termo de Inscrição para Concursos (1913-1948). Ref. 417FASS06. 


\section{Livro de visitas do Atheneu Sergipense (1916-1951).}

CHERVEL, André. História das disciplinas escolares: reflexões sobre um campo de pesquisa. Trad. Guacira Lopes Louro. Teoria \& Educação, Porto Alegre, n. 2, p. 177-229, 1990.

DALLABRIDA, Norberto; SOUZA, Rosa Fátima. "O todo-poderoso império do meio": as transformações no ensino secundário entre a Reforma Francisco Campos e a primeira LDBEN (à guisa de apresentações). In: DALLABRIDA, Norberto; SOUZA, Rosa Fátima (Orgs.). Entre o ginásio e o colégio popular: estudos sobre o ensino secundário no Brasil (1931-1961). Uberlândia: Edufu, 2014. p. 11-30.

FERREIRA, Marcela de Almeida; GRANATO, Marcus; BRASIL, Zenilda F.; CALVÃO, Alexandre. O conjunto de objetos de ensino do laboratório de Física do Colégio Pedro II. In: GRANATO, Marcus; LOURENÇO, Marta C. (Orgs.). Coleções Científicas LusoBrasileiras: patrimônio a ser descoberto. Rio de Janeiro: Mast, 2010.

GOODSON, Ivor F. Currículo, teoria e história. Petrópolis: Vozes, 2001.

. Historia del currículum: la construcción social de las disciplinas escolares. Barcelona: Ediciones Pomares - Corredor, 1998.

Tornando-se uma matéria acadêmica: padrões de explicações e evolução. Teoria \& Educação, n. 2, 1990.

GOODSON, Ivor; DOWBIGGIN, Ian R. La historia del currículum, la profesionalización y la organización social del conocimiento. In: GOODSON, Ivor. Estudio del currículum: casos y métodos. Buenos Aires: Amorrortu, 2003.

GUARANÁ, Armindo. Diccionário bio-bibliografico sergipano. Rio de Janeiro: Pongetti, 1925.

JULIA, Dominique. Disciplinas escolares: objetivos, ensino e apropriação. In: LOPES, Alice Casimiro; MACEDO, Elizabeth (Orgs.). Disciplinas e integração curricular: história e políticas. Rio de Janeiro: DP\&A, 2002.

LORENZ, Karl Michael. A influência francesa no ensino de ciências e matemática na escola secundária brasileira no século XIX. In: CONGRESSO BRASILEIRO DE HISTÓRIA DA EDUCAÇÃO, II, 2002, Natal. Anais... Natal: Universidade Federal do Rio Grande do Norte, 2002.

LORENZ, Karl Michael. O ensino de Ciências e o Imperial Collegio Pedro II: 1838-1889. In: VECHIA, Ariclê; CAVAZOTTI, Maria Auxiliadora (Orgs.). A Escola Secundária: modelos e planos (Brasil, séculos XIX e XX). São Paulo: Annablume, 2003.

MELONI, Reginaldo Alberto. A experiência de constituição de uma fonte documental a partir dos instrumentos de ensino de química e física do Colégio Culto à Ciência de Campinas/SP. Revista Brasileira de História da Educação, SBHE, Ed. Autores Associados, SP-Campinas, v. 11, n. 1 (25), p. 43-65, jan./abr. 2011.

MELONI, Reginaldo Alberto. Patrimônio educativo na escola secundária: os "objetos de educação em ciências". In: CONGRESSO LUSO-BRASILEIRO DE HISTÓRIA DA EDUCAÇÃO, X, 2014, Curitiba. Anais... Curitiba: Pontifícia Universidade Católica do Paraná, 2014.

MORSE, Richard. Formação histórica de São Paulo. Corpo e alma do Brasil. São Paulo: Difusão européia do livro, 1970.

OLIVEIRA, Marcus Aurélio Taborda de; RANZI, Serlei Maria Fischer (Orgs.). História das disciplinas escolares no Brasil: contribuições para o debate. Bragança Paulista: Edusf, 2003. 
OLIVEIRA, João Paulo Gama. Caminhos cruzados: itinerários de pioneiros professores do Ensino Superior em Sergipe. (1915-1954). 2015. 319 f. Tese (Doutorado em Educação) - Programa de Pós-Graduação em Educação da Universidade Federal de Sergipe, São Cristóvão, 2015.

PESSANHA, Eurize Caldas. História de disciplinas escolares em uma escola exemplar em Mato Grosso do Sul: possibilidades de uma história da cultura escolar (1939-2002).

Revista Tempos e Espaços em Educação, São Cristóvão, v. 4, n. 4, p. 31-41, jan. 2010. PESSANHA, Eurize Caldas; DANIEL, Maria Emília Borges; MENEGAZZO, Maria Adélia. Da história das disciplinas escolares à história da cultura escolar: uma trajetória de pesquisa. Revista Brasileira de Educação [online], n. 27, p. 57-69, 2004.

PESSANHA, Eurize Caldas; OLIVEIRA, Stella Sanches de; ASSIS, Wanderlice da Silva. Muito além de "papéis velhos": fontes para a história de disciplinas escolares armazenadas em um arquivo escolar. Revista Educação em Questão, Natal, v. 41, n. 27, p. 164-191, julho 2011.

SAMPAIO, Glads Maria D’Elia. A história do ensino de Física no Colégio Pedro II de 1838 até 1925. 2004. 172 f. Dissertação (História das Ciências e das Técnicas e Epistemologia) - Coppe/UFRJ, Rio de Janeiro, 2004.

SANTANA, Sayonara Rodrigues do Nascimento. Por entre as memórias de uma instituição: o arquivo e as práticas administrativas do Atheneu Sergipense (1870-1926). 2012. 159 f. Dissertação (Mestrado em Educação) - Programa de Pós-Graduação em Educação da Universidade Federal de Sergipe, São Cristóvão, 2012.

SANTOS, Nadja Paraense dos. Pedro II, sábio e mecenas, e sua relação com a Química. Revista da SBHC, Rio de Janeiro, v. 2, n. 1, p. 54-64, jan./jun. 2004.

SCHEFFER, Elizabeth Weinhardt. Química: ciência e disciplina curricular, uma abordagem histórica. 1997. Dissertação (Mestrado em Educação) - Programa de PósGraduação em Educação da Universidade Federal do Paraná, Curitiba,1997.

SCHNETZLER, Roseli Pacheco. Um estudo sobre o tratamento do conhecimento químico em livros didáticos brasileiros dirigidos ao Ensino Secundário de Química de 1875 a 1978. Química Nova, São Paulo, n 1, p. 6, 1981.

SOUZA, Roberto Acízelo de. 0 império da eloquência: retórica e poética no Brasil oitocentista. Rio de Janeiro: Editoras Uerj, UFF, 1999.

SOUZA, Rosa Fátima de. Fotografias escolares: a leitura de imagens na história da escola primária. Educar em Revista, Curitiba/PR, Ed. da UFPR, n. 18/2001.

SOUZA, Suely Cristina Silva. "Habilitado" ou "Inhabilitado": os concursos para professores do Ensino Secundário em Sergipe (1875-1947). 2016. 360 f. Tese (Doutorado em Educação) - Programa de Pós-Graduação em Educação, Universidade Federal de Sergipe, São Cristóvão/SE, 2016.

SOUZA, Suely Cristina Silva. Uma história da disciplina matemática no Atheneu Sergipense durante a ação da Reforma Francisco Campos (1938-1943). 2011, 252 f. Dissertação (Mestrado em Educação) - Programa de Pós-Graduação em Educação, Universidade Federal de Sergipe, São Cristóvão/SE, 2011.

TORRES, Mariana Cassab. A emergência da disciplina biologia escolar (1961-1981): renovação e tradição. 2011, 238 f. Tese (Doutorado em Educação) - Programa de PósGraduação em Educação, Universidade Federal Fluminense, Niterói, 2011.

VECHIA, Ariclê; LORENZ, Karl Michael. Programa de ensino da escola secundária brasileira (1850-1951). Curitiba: Ed. do Autor, 1998. 
VIDAL, Diana Gonçalves; ABDALA, Rachel Duarte. A fotografia como fonte para a história da educação: questões teórico-metodológicas e de pesquisa. Educação (UFSM), Santa Maria, v. 30, p. 177-194, 2005. Disponível em: <http://www.fundaj.gov.br/geral/educacao foco/historia-educa.pdf>. Acesso em: 20 jun. 2014.

VIÑAO, Antonio. A história das disciplinas escolares. Revista Brasileira de História da Educação [online], n. 18, p. 173-215, 2008.

EVA MARIA SIQUEIRA ALVES é professora titular da Universidade Federal de Sergipe, aposentada e voluntária no Programa de Pós-graduação em Educação. Coordena o Centro de Educação e Memória do Atheneu Sergipense (Cemas). Líder do Grupo de Pesquisa Disciplinas Escolares: História, Ensino e Aprendizagem (Dehea/UFS/CNPq).

Endereço: Avenida Ivo do Prado, 1182 - ap. 1001, Edifício Olímpio Campos, 49015-070, São José, Aracaju/SE, Brasil.

E-mail: evasa@uol.com.br

JOÃO PAULO GAMA OLIVEIRA é doutor em Educação e professor do Departamento de Educação (Dedi) da Universidade Federal de Sergipe.

Endereço: Avenida Deputado Sílvio Teixeira, 1105 - ap. 701, Condomínio Versatto Jardins, Dália, 49025-100, Jardins, Aracaju/SE, Brasil.

E-mail: profjoaopaulogama@gmail.com

Recebido em 24 de agosto de 2017.

Aceito em 21 de junho de 2018. 